\title{
Internal Friction Angle of Metal Powders
}

\author{
Jiri Zegzulka ${ }^{1,2}$, Daniel Gelnar ${ }^{1}$, Lucie Jezerska ${ }^{1, *}$ (D) , Alvaro Ramirez-Gomez ${ }^{3}$, Jan Necas ${ }^{1,2}$ \\ and Jiri Rozbroj ${ }^{1}$ \\ 1 VSB-TU Ostrava, ENET CENTRE-Energy Utilization of Non-traditional Energy Sources, Bulk Solids Centre, \\ 17. listopadu 15, 70833 Ostrava, Czech Republic; jiri.zegzulka@vsb.cz (J.Z.); daniel.gelnar@vsb.cz (D.G.); \\ jan.necas@vsb.cz (J.N.); jiri.rozbroj@vsb.cz (J.R.) \\ 2 VSB-TU Ostrava, Faculty of Mechanical Engineering, Institute of Transportation, 17. listopadu 15, \\ 70833 Ostrava, Czech Republic \\ 3 Technical University of Madrid, Department of Mechanical, Chemical and Industrial Design Engineering, \\ Ronda de Valencia 3, 28012 Madrid, Spain; alvaro.ramirez@upm.es \\ * Correspondence: lucie.jezerska@vsb.cz; Tel.: +420-597-329-430
}

Received: 25 January 2018; Accepted: 6 April 2018; Published: 10 April 2018

\begin{abstract}
Metal powders are components with multidisciplinary usage as their application is very broad. Their consistent characterization across all disciplines is important for ensuring repeatable and trouble-free processes. Ten metal powders were tested in the study. In all cases, the particle size distribution and morphology (scanning electron microscope-SEM photos) were determined. The aim of this work was to inspect the flow behavior of metal powders through another measured characteristic, namely the angle of internal friction. The measured values of the effective internal friction angle in the range $28.6-32.9^{\circ}$, together with the spherical particle shape and the particle size distribution, revealed the likely dominant mode of the metal particle transfer mechanism for stainless steel 316L, zinc and aluminum powder. This third piston flow mechanism is described and illustrated in detail. The angle of internal friction is mentioned as another suitable parameter for the characterization of metal powders, not only for the relative simplicity of the determination but also for gaining insight into the method of the movement of individual particles during the flow.
\end{abstract}

Keywords: metal powders; particle size distribution; particle shape; angle of internal friction; piston mechanism

\section{Introduction}

Metal powders, i.e., fine metal particles, are the basis for many areas of modern industrial production from powder metallurgy, paint-making industry, medicine to pyrotechnics. The market for metal powders, therefore, exponentially rises with the development of other manufacturing techniques for metal systems such as the additive manufacturing (AM), including powder bed fusion (PBF), direct energy deposition (DED) and binder jetting using metal powders as the primary source of material to form components. The PBF and DED techniques use direct melting of powder materials to create fully dense parts using high-energy sources (laser, electric beams), while the binder jetting method uses the precipitation of pulverized particles with adhesive agents before subsequent sintering and secondary infiltration for partial restoration of the parts. Above all, powder bed fusion (PBF), including the selective laser melting (SLM) processes and electron beam melting (EBM), is the preferred direct production option of high-quality metal parts from metal powders [1-3]. The characterization of input metal powder was dealt with in several studies [4-6]. In traditional layered methods (LM-laser melting, 3D Printing, SLS—selective laser sintering, SLM, etc.), input powders are characterized, for example, by morphology, granulometry, surface parameters (packing density), rheology or thermal properties known to affect the behavior of raw materials during the production of metal parts. Good 
flow and high packing density of metal powders [7] are desirable in all the production techniques mentioned. These parameters are mainly dependent on the particle shape, particle size distribution and internal friction angle. The particle size distribution is usually presented as a differential (distribution) curve with the differentiation of the mode, mean (average) and median of the particle size of the input metal powder and as a cumulative curve that identifies the volume content in terms of size $\left(d_{10}\right.$, $d_{50}$ and $d_{90}$ ). Various particle size distributions lead to the production of various packing behaviors which, for instance, influence the shrinkage and the densification of molding parts in conventional sintering processes and other manufacturing procedures [8]. The authors of another study on the granulometry of input metal powders, which may affect the ability to process the material throughout the manufacturing process, determined stated the preliminary requirements for the particle size distribution particularly suited to additive production (including SLS and SLM) [9]:

$$
d_{90}<t_{\text {layer }}, \frac{d_{50}}{d_{10}} \geq 10, \frac{d_{90}}{d_{10}} \leq 19
$$

This are the so called Karapatis derived criteria $[10,11]$, where $t_{\text {layer }}$ is the thickness of the powder layer for the additive technology, $d_{10}, d_{50}$ and $d_{90}$ indicate $10 \%, 50 \%$ or $90 \%$ of the particle representation for the measured dimension. These criteria indicate that $50 \%$ of the particles are 10 times coarser than $10 \%$ of finer particles (grains), at the same time about $20 \%$ of the particle size is in the ratio of 1:20. These requirements were originally set for bimodal particle size distributions and adapted for monomodal distributions. It was searched out that for $d_{10}<5-6 \mu \mathrm{m}$ these fine metal particles begin to agglomerate. This phenomenon reduces the flowability, consequently, it is difficult to form a suitable homogeneous powder layer with the required density [12].

The angle of internal friction, which determines the failure properties of the particle assembly under stress, is another fundamental characteristic of the metal powder flow [13]. Several authors studied the effect of shape on the internal friction angle of metal powders [13-15]. Their studies state that the angle of internal friction increases with decreasing particle size along with deviations from the spherical surface. With the increasing particle angularity, the initial free space is reduced, and the interlocking effect is increased. For the present, the systematic research of the internal friction angle of metal particles of various shapes and sizes in this area is very limited. The angle of internal friction can be defined as the rate of loss of work in the flow of powder materials. This gives a complex flow efficiency term, which should indicate the energy balance of the powder movement more efficiently than the traditional concept of the internal friction angle [16].

In the first part of this work, ten metal powders are characterized by particle size distributions, their morphology and the values of the internal friction angles in relation to the processes of powder metallurgy are demonstrated. These are zinc, aluminum, 316L stainless steel, copper, bronze, iron, manganese, titanium, tin and ferrite powder. The second section provides the application of the theory of the particle position change in the flow of metal powders based on the internal friction angle expressed as the rate of loss of work, in other words an insight into the behavior of metal powders.

\section{Materials, Methods and Model}

\subsection{Materials}

Ten different metal powders were used for experiments. Metal powders were selected with relation to their commercial availability (metal powder market). Stainless steel 316L was taken from the production of 3D printing, zinc, aluminum, tin, copper, iron, bronze and titanium powder are commercially available metal powders produced by the company Fichema (Brno, Czech Republic). Manganese powder is a metal powder produced by the company Pkchemie (Trebic, Czech Republic). Ferrite powder was taken from the production of permanent magnets. 


\subsection{Methods}

\subsubsection{Particle Size Distribution}

The granulometric analysis of the metal powder sample was performed on the Cilas 1190 laser analyzer (Cilas, Orleans, France). Cilas uses Fraunhofer diffraction. This method is widely used for particle size measurement [17]. The wet path method was implemented. Water was the medium used in the tests. The metal powders were measured after sonication to ensure complete dispersion. The determination of the particles size was conducted based on the passage of the measured material dispersed in the carrier medium through coherent light with a wavelength of $830 \mathrm{~nm}$. The results and evaluations are usable directly from the Cilas device $[18,19]$. One measurement was repeated 3 times. The resulting parameters $d_{10}, d_{50}$ and $d_{90}$ are the average values.

\subsubsection{Angle of Internal Friction and Flow Function}

Angle of internal friction measurement was done on the shear testing machine (Schulze Ring Shear Tester) RST-01 (Wolfenbuttel, Germany). Angle of internal friction is an important descriptive parameter of bulk solids for various applications [20]. Principle of its evaluation is based on metering of the stable value of shear stress depending on the normal load [21,22]. The bulk density of the sample is changing during the metering depending on the consolidation of defined normal load and its average value is the result. The shear stress in test sample arise from the rotation of the shear cell that is turning against the cap. The cap that does not rotate is connected to the force sensors indicating the effects of rotation as an acting force. Figure 1 shows the RST-01 output with description of the most significant parameters. To these parameters belongs for example also the effective angle of internal friction $\delta$, linearized angle of internal friction $\varphi$, cohesion $c$, major principal stress $\sigma_{1}$ and unconfined yield strength $\sigma_{\mathrm{c}}$. The measurement done for this paper is focused on the effective angle of internal friction. The major part of the RST-01 output data is just in connection with this very value. Angle of internal friction is under contemporary state of technology measured by experimental methods.

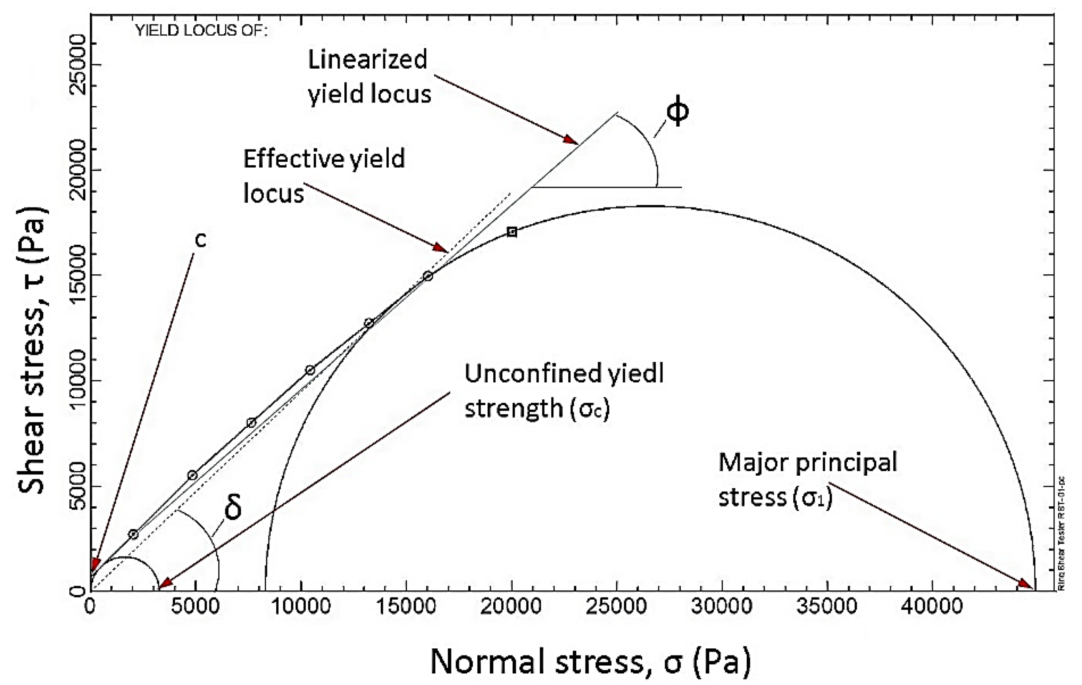

Figure 1. Schematic diagram of powder yield locus obtained from the Schulze ring tester.

The angle of internal friction was measured for each metal powder 10 times for 3 normal stress settings-5000 Pa, 10,000 $\mathrm{Pa}$ and 20,000 Pa. The resulting angles of internal friction (linearized, effective) for individual metal powders are the average values of 30 measurements.

The relationship between the unconfined yield strength $\sigma_{\mathrm{c}}$ and the major principal stress $\sigma_{1}$ is called the flow function $\mathrm{ffc}$ of the powders. The metal powders were characterized by the ratio $\mathrm{ffc}=\sigma_{1} / \sigma_{\mathrm{c}}$. The larger $\mathrm{ffc}$, the more easily the bulk materials flow [23]. 


\subsection{Angle of Internal Friction Model}

The internal friction angle model details the method of moving individual metal powder particles for the piston particle motion mechanism (1), which was defined by prof. Zegzulka [16]. The term is of historical character. The schematic representation of this first mechanism is shown in Figure 2. Individual particle shifts are defined as a degree of energy intensity that is given by the angle of internal friction. It is essentially a value representing the mechanical difficulty of moving one particle from its initial position to its final position. Therefore, the angle of internal friction can represent the physical quantity known as the "mechanical efficiency" of the mutual transformation of the forms of energy $\mathrm{W}_{\text {kinetic }} \rightarrow \mathrm{W}_{\text {potential }} \rightarrow \mathrm{W}_{\text {pressure }} \rightarrow \mathrm{W}_{\text {dissipation }}$.

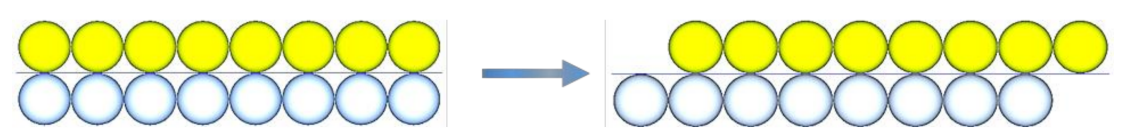

Figure 2. Schematic representation of the piston flow mechanism (1) [16].

The first possibility of moving a particle between two positions, the initial and final one is shown in Figure 2. The monitored particle copies the shape of the surface to which is bound, by means of which its trajectory of motion is determined. Around the first mechanism, where the particles do not pass through the shear plane, there are 5 basic types of motion. Prof. Zegzulka provides the detailed specification of partial particle movement mechanisms according to the first piston flow mechanism (1) in his publication [16]. This mechanism is valid for the internal friction angle ranging from $5.66^{\circ}$ to $30.36^{\circ}$.

The second mechanism of moving, that helps with transfer of particles in bulk solids with angle of internal friction bigger than $30.36^{\circ}$ is casing mechanism (2) [24]. In this case, the transferring of particles is caused by their mutual exchange. This particle exchange runs in the shear level. The resulting vector of movement follows the direction of bulk solid flow.

\section{Results and Discussion}

\subsection{Particle Characterization}

The particle size distributions of the first five metal powders are shown in Figure 3, another five in Figure 4 and the $d_{10}, d_{50}$ and $d_{90}$ values are summarized in Table 1.

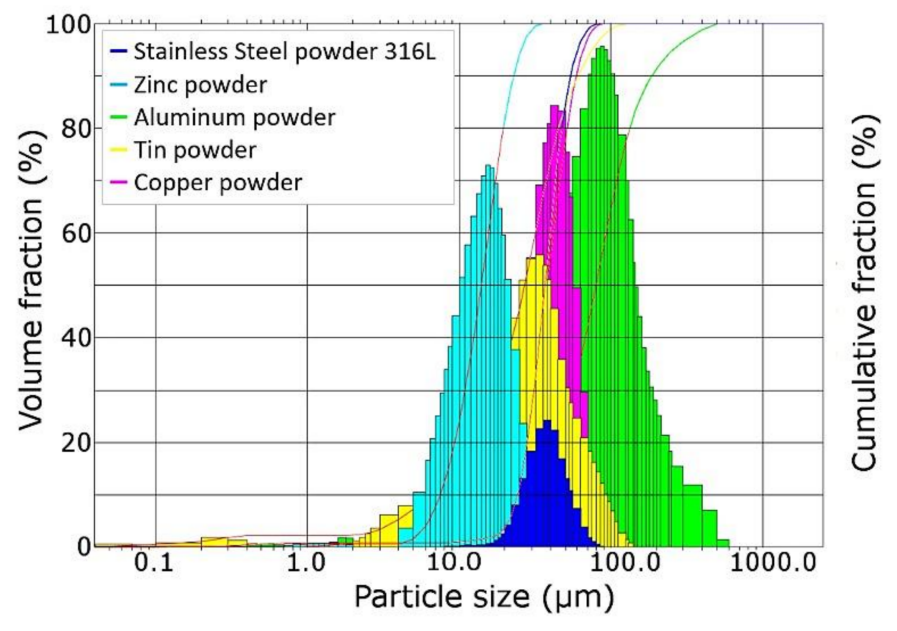

Figure 3. The particle size distribution (differential and cumulative) for the first five metal powders. 


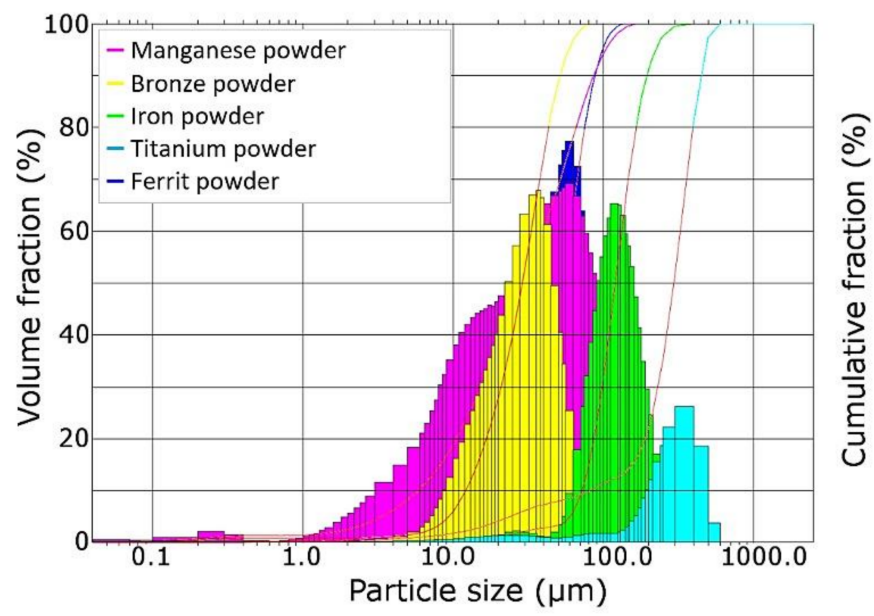

Figure 4. The particle size distribution (differential and cumulative) for another five metal powders.

Table 1. Characteristics values for the particle size distribution.

\begin{tabular}{cccccc}
\hline Metal Powders & $\boldsymbol{d}_{\mathbf{1 0}}(\boldsymbol{\mu \mathrm { m }})$ & $\boldsymbol{d}_{\mathbf{5 0}}(\boldsymbol{\mu \mathrm { m } )}$ & $\boldsymbol{d}_{\mathbf{9 0}}(\boldsymbol{\mu \mathrm { m } )}$ & $\boldsymbol{d}_{\mathbf{5 0}} / \boldsymbol{d}_{\mathbf{1 0}}$ & $\boldsymbol{d}_{\mathbf{9 0}} / \boldsymbol{d}_{\mathbf{1 0}}$ \\
\hline Stainless Steel 316L & $26.0 \pm 0.8$ & $38.8 \pm 0.1$ & $58.0 \pm 0.1$ & 1.5 & 2.2 \\
Zinc powder & $8.3 \pm 0.1$ & $15.8 \pm 0.2$ & $24.8 \pm 0.4$ & 1.9 & 3.0 \\
Aluminum powder & $29.4 \pm 0.2$ & $79.1 \pm 0.4$ & $187.3 \pm 5.0$ & 2.7 & 6.4 \\
Tin powder & $6.3 \pm 0.3$ & $26.9 \pm 0.4$ & $59.1 \pm 1.8$ & 4.3 & 9.3 \\
Copper powder & $16.1 \pm 0.1$ & $35.6 \pm 0.1$ & $57.5 \pm 0.2$ & 2.2 & 3.6 \\
Manganese powder & $6.1 \pm 0.2$ & $32.3 \pm 1.2$ & $88.0 \pm 1.6$ & 5.3 & 14.5 \\
Bronze powder & $12.1 \pm 0.1$ & $29.6 \pm 0.2$ & $57.2 \pm 1.4$ & 2.4 & 4.7 \\
Iron powder & $72.7 \pm 0.2$ & $121.1 \pm 0.5$ & $195.1 \pm 0.5$ & 1.7 & 2.7 \\
Titanium powder & $80.7 \pm 1.6$ & $295.1 \pm 0.5$ & $452.1 \pm 0.2$ & 3.7 & 5.6 \\
Ferrite powder & $29.2 \pm 0.4$ & $54.9 \pm 0.7$ & $86.6 \pm 3.0$ & 1.9 & 3.0 \\
\hline
\end{tabular}

Based on $d_{90}$ parameter, titanium powder contained the largest particles $(452 \mu \mathrm{m})$, whereas, zinc powder contained the smallest particles $(25 \mu \mathrm{m})$. For most metal powders, however, $90 \%$ of the particles ranged from about 60 to $90 \mu \mathrm{m}$. It can be concluded from the values that manganese powder has the widest span of particle distribution, which is also evident from the shape of the distribution curve (Figure 4) and from the SEM photograph shown as a part of Figure 5. The symmetrical distribution of the particle size is evident, e.g., by zinc powder (Figure 3). The SEM photographs suitably complement the characterization of metal powders (Figure 5). The aforementioned manganese powder contains sharp-angled particles of various sizes. Smaller particles can fill the gap between the larger ones to ensure proper packing behavior. Stainless steel 316L and zinc powder contain separate spherical particles whose geometrical shape is close to the sphere. Aluminum powder contains, in addition to spherical particles, a minimum proportion of droplet-shaped particles whose exterior appearance is close to the ellipsoid. The photograph also proves that the smaller particles cover the surface of larger ones. Tin powder contains a considerable number of fine particles but also larger grains. The distribution span is wide. The particles are spherical or droplet-shaped and separated. Copper powder is composed of grains of irregular shape without geometric regularity. Bronze powder contains a mixture ranging from spherical particles to irregular shaped particles. Iron powder can be partly characterized by a sheet-like form of larger clumps. Titanium powder contains the largest particles, some with a dendritic shape. In the case of ferrite powder, there are agglomerates of fine, sharp-edged particles, either separate or packing coarser grains. 


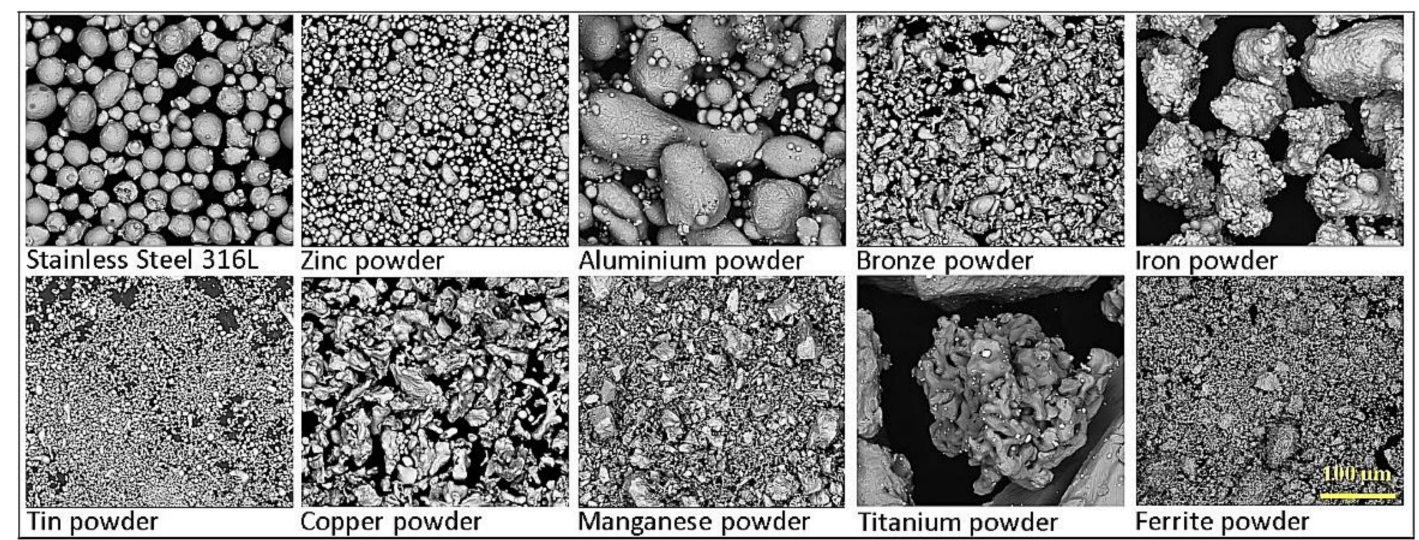

Figure 5. Scanning electron microscope (SEM) photos of metal powders depicting the shape and the structure of particles.

The last two columns of Table 1 provide values for the preliminary assessment of the level of suitability of metal powder granulometry for the additive SLS and SLM production, according to Karapatis criteria (Equation (1)). The $d_{50} / d_{10}>10$ criterion has not been fully met for any of the studied metal powders, although, for example, 316L stainless steel is used in additive production without problems. This ratio ranged from 1.5 to 5.3 when the highest value corresponds to the manganese powder. The value suggests that $50 \%$ of the particles are 5 times larger than $10 \%$ of finer particles. On the other hand, the $d_{90} / d_{10} \leq 19$ criterion was met for all metal powders tested. As for metal powders examined by us, it applies that $d_{90} / d_{10} \leq 15$. This requirement meets the condition of filling the free spaces between the coarse particles by fine grains to form the effective layer. Similar results regarding non-fulfilment/fulfilment of the criteria were also achieved in another study [12]. Therefore, another complementary criterion qualitatively specifying the suitability of metal powder granulometry for additive technology should be specified. To conclude from results, there is a certain balance between the stated ratios. Larger amounts of fine particles (up to about $6 \mu \mathrm{m}$ ) are agglomerated, while large amounts of larger particles often cause uneven (rough) surfaces. Both conditions are, therefore, marginal to create a suitable homogeneous powder layer for additive production. A further alternative of the addition is the determination of another characterization parameter, for instance the angle of internal friction.

\subsection{Angle of Internal Friction}

The knowledge of the particle arrangement structure (together with the filling of the empty inter-particle spaces) is essential for creating an effective homogeneous powder layer in additive powder technologies. The internal friction angle of metal powders is the reference value for this arrangement. The measured values of the effective internal friction angle and the internal friction angle for the ten metal powders are given in Table 2. 
Table 2. Effective internal friction angle $(\delta)$ with standard deviation of measurement $\left(\sigma_{\text {sd }}\right)$, minimum $\left(\delta_{\min }\right)$ and maximum value $\left(\delta_{\max }\right)$ for individual metal powders. Internal friction angle $(\phi)$ with standard deviation $\left(\sigma_{\mathrm{sd}}\right)$, minimum $\left(\phi_{\min }\right)$ and maximum value $\left(\phi_{\max }\right)$ for individual metal powders.

\begin{tabular}{ccccccccc}
\hline Metal Powders & $\boldsymbol{\delta}\left({ }^{\circ}\right)$ & $\boldsymbol{\sigma}_{\text {sd }}\left({ }^{\circ}\right)$ & $\boldsymbol{\delta}_{\min }\left({ }^{\circ}\right)$ & $\boldsymbol{\delta}_{\max }\left({ }^{\circ}\right)$ & $\boldsymbol{\phi}\left(^{\circ}\right)$ & $\boldsymbol{\sigma}_{\text {sd }}\left({ }^{\circ}\right)$ & $\boldsymbol{\phi}_{\min }\left({ }^{\circ}\right)$ & $\boldsymbol{\phi}_{\max }\left({ }^{\circ}\right)$ \\
\hline Stainless Steel 316L & 28.6 & 0.5 & 28.0 & 39.7 & 28.5 & 0.4 & 27.8 & 29.3 \\
Zinc powder & 29.9 & 0.3 & 29.3 & 30.7 & 29.6 & 0.5 & 28.8 & 30.7 \\
Aluminum powder & 32.9 & 1.2 & 31.4 & 35.2 & 32.9 & 1.2 & 31.4 & 35.2 \\
Tin powder & 37.8 & 2.8 & 33.8 & 42.2 & 36.1 & 1.8 & 33.3 & 38.8 \\
Copper powder & 39.1 & 0.7 & 38.2 & 40.6 & 38.1 & 0.5 & 37.4 & 39.1 \\
Manganese powder & 39.4 & 0.4 & 38.9 & 40.6 & 38.6 & 0.6 & 37.9 & 40.4 \\
Bronze powder & 39.9 & 0.5 & 39.0 & 40.7 & 38.7 & 0.7 & 37.6 & 40.1 \\
Iron powder & 40.0 & 0.7 & 39.0 & 41.6 & 39.4 & 0.5 & 38.7 & 40.7 \\
Titanium powder & 42.9 & 0.9 & 41.4 & 45.1 & 41.9 & 0.7 & 40.6 & 43.7 \\
Ferrite powder & 48.1 & 1.6 & 45.8 & 51.1 & 39.1 & 0.6 & 37.6 & 40.0 \\
\hline
\end{tabular}

Regarding the above stated data, the metal powders are arranged with an increasing value of the internal friction angle (both efficient and linearized). 316L stainless steel used in 3D printing contains spherical particles with the internal friction angle effective value of $28.6 \pm 0.5^{\circ}$. The ideal bulk material, as is known, corresponds to the $30^{\circ}$ angle of internal friction $[16,23,25]$. Its definition is: "Ideal bulk is formed by spheres. The magnitude of the internal friction angle of the ideal bulk mass is equal to the angle of repose and it is $30^{\circ}$. The angle of repose is invariant to external and internal influences in the case of the ideal bulk material." Metal powders approaching this quality would probably meet the requirements for additive production of SLM or EBM. Information to the $30^{\circ}$ angle of internal friction are briefly summarized as follows:

- In case of the bulk solid where the angle of internal friction is $\alpha<30^{\circ}$ all particles are having all possibilities to change their position - the first mechanism, the piston one (1)—does not come through the theoretical shear level.

- In case of the bulk solid where the angle of internal friction is $\alpha>30^{\circ}$ all particles are having all possibilities to change their position—the second mechanism, the casing one (2)—does come through the theoretical shear level.

- This is therefore the limiting, threshold value among the mechanisms mentioned. $30^{\circ}$ is the boundary line between the areas mentioned above.

- Bulk solid having the angle of internal friction $30^{\circ}$ in case of the free poured pile again forms an angle $30^{\circ}$, which means that the angle of repose equals also $30^{\circ}$.

Zinc powder, which contains smooth, separated spherical particles with an average size of $16 \mu \mathrm{m}$ is the closest to this value $\left(30^{\circ}\right)$ of the internal friction angle of the "ideal bulk mass". Gaussian distributions of the incidence of effective internal friction angle values for all tested metal powders are shown in Figure 6. The largest range of values of the effective internal friction angle was found in tin powder, the lowest range in zinc powder. The most frequent data occurred in the range from $37.5^{\circ}$ to $43^{\circ}$.

316L stainless steel and aluminum powder are other powdered metals whose value of the internal friction angle indicates suitability for additive technology. For aluminum powder, the value is already slightly higher equaling to $32.9 \pm 1.2^{\circ}$.

Figure 7 depicts dependence of flow function ffc on the effective angle of internal friction. In this diagram two groups of materials can be seen. On the left there are metal powders usable for additive manufacturing with respect to flowability parameter, e.g., interference with application of powder layer ( $\mathrm{ffc}=\mathrm{f}($ angle of internal friction) $)$. Values of their effective angles of internal friction can be found in proximity of the value of ideal bulk solid, which is $30^{\circ}$. On the right (marked red) there is a group of metal powders with worse flowability (lower ffc value) and higher angle of internal friction values. 


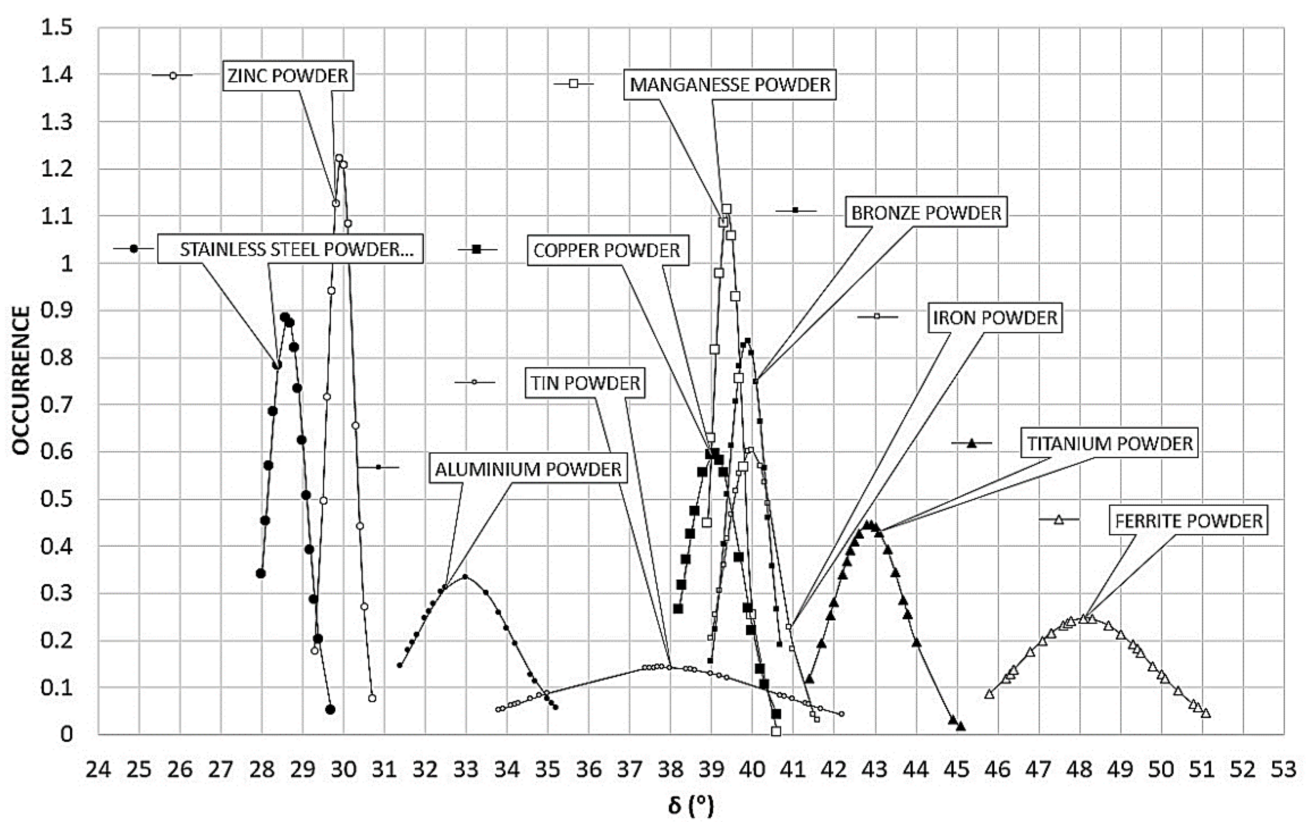

Figure 6. Occurrence of the effective internal friction angle for all tested metal powders.

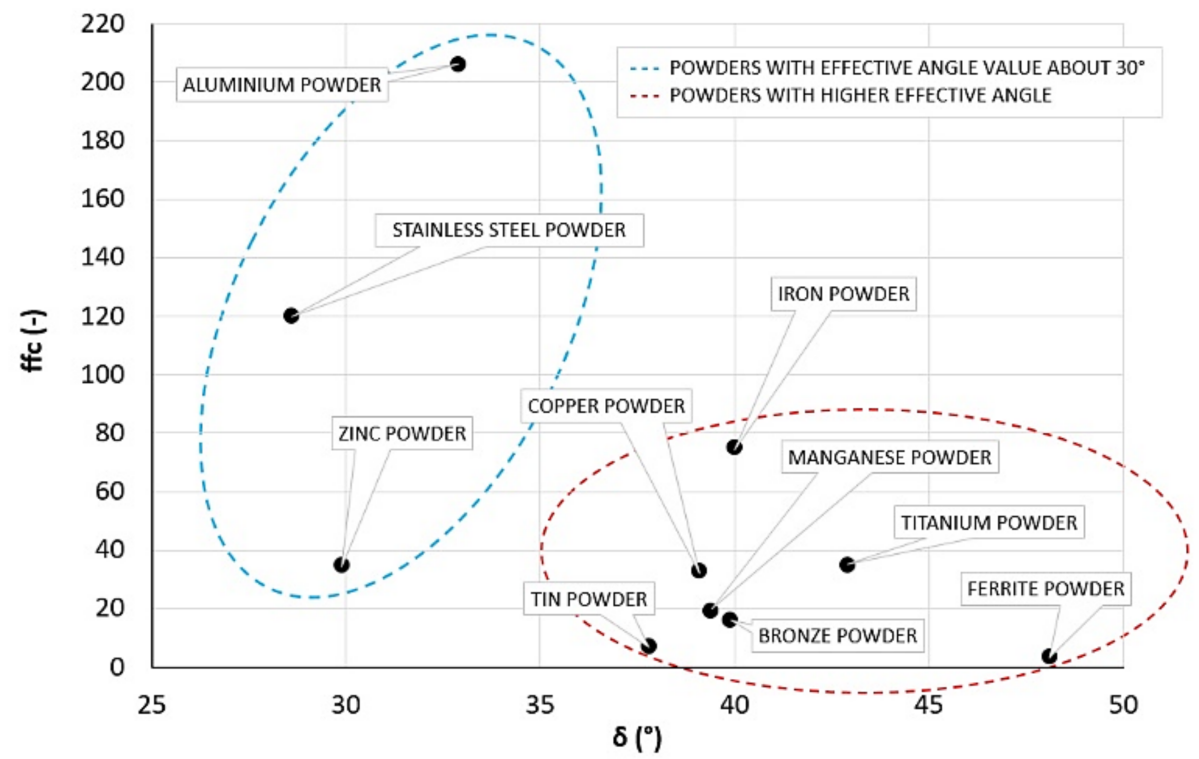

Figure 7. Relation between flow function $\mathrm{ffc}$ and effective angle of internal friction $\delta$. (- - - metal powders suitable for additive manufacturing, _- - metal powders with worse flowability).

The practical application of the internal friction angle model is based on the structure of the deposition of metal powder particles (the way they are arranged). The internal friction angle model is based on the knowledge of two principal mechanisms of particle position change (Section 2.3). The piston mechanism (1) of particle motion is the mechanism where the particles do not pass through the shear plane but follow the shape of the surface to which they are bound. It copies the motion trajectory. The casing mechanism (2) is the second flow mechanism. The particle position change is done through the plane of shear. To the first mechanism of metal powder particle transition-the piston mechanism (1) where the angle of internal friction is within the range of 5.66-30.36 ${ }^{\circ}$, there are five possible types of particle transfer (1.1-1.5) as shown in Figure 8. 


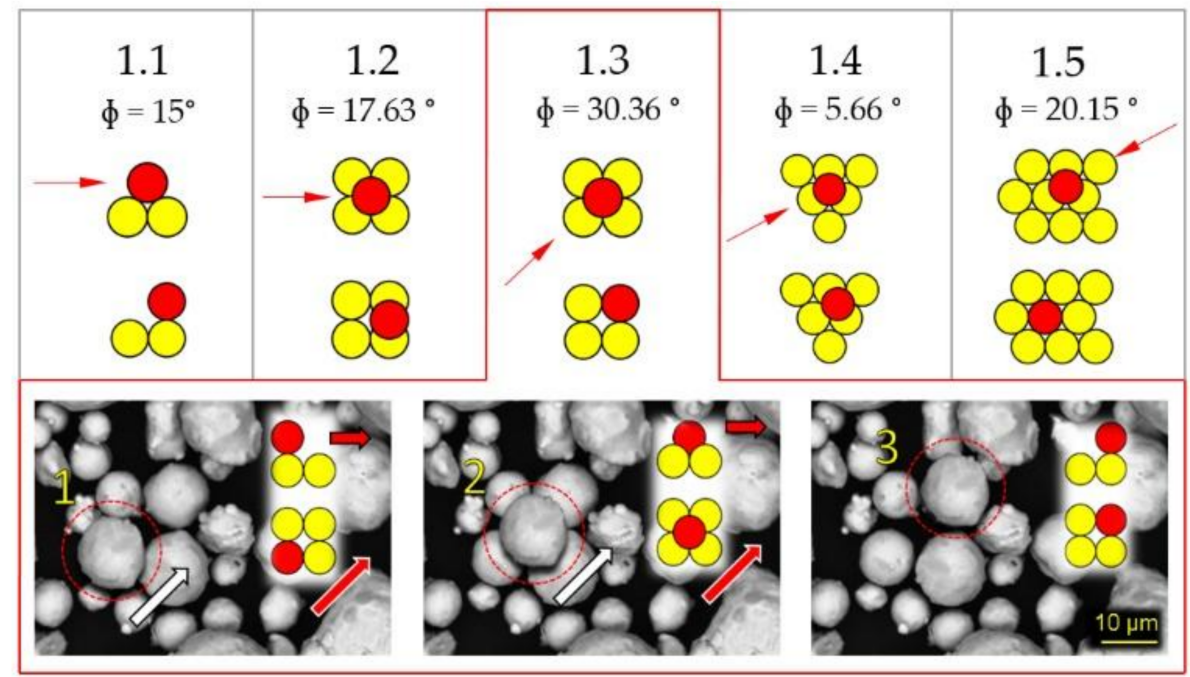

Figure 8. Schematic representation of piston flow mechanism (1) with types of particle motion (1.1-1.5). Detailed visualization for zinc powder-type of particle motion 1.3. 1-initial position, 2-middle position and 3-final position of zinc particle.

As mentioned above, the first three metal powders, namely stainless steel 316L, zinc and aluminum powder have an internal friction angle of about $30^{\circ}$. This value predicts the piston mechanism (1) of particle flow. Therefore, the particles of these three powders will move in one shear plane, specifically by the third type of shift [16]. This method of moving particles is shown in more detail in Figure 8. This is a movement of the particle along the diagonal of the bottom layer. The situation is described by the red marked zinc powder particle passing from the initial position (Figure 8, Marking 1) to the final position (Figure 8, Marking 3). The loss of work is proportional to the path movement of the metal powder zinc particle between the initial and the final positions. The solution of all partial mechanisms of the piston flow is conditioned by the regular arrangement of particles, which is not achievable in the practical conditions of the production process. It is merely achievable to approximate this state and to show it schematically.

It is important to note that the flow of the discussed metal powders-316L stainless steel, zinc powder and aluminum powder-does not occur by means of merely the third mechanism shown, but it is obvious that it will be dominant due to the magnitude of the internal friction angle.

As the measured values proved stainless steel 316L and zinc powder are proportionally of different size. In distributions $d_{10}, d_{50}$ and $d_{90}$ it is by more than twice in ratio. This size difference, however, had not substantial impact on the resulting values of effective angle of internal friction $\delta$, they differ solely by $1.3^{\circ}$. The slight difference of $\delta$ between stainless steel 316L and zinc powder results from the particle shape, which is close to a spherical shape as it is apparent from the Figure 5. The sample of copper powder is the closest to stainless steel $316 \mathrm{~L}$ by the particle size in distributions $d_{10}, d_{50}$ and $d_{90}$. The difference of effective angle of internal friction $(\delta)$ between the samples equals to $10.5^{\circ}$ and results from the particle shape (Figure 5). As for the value of effective internal friction angle ( $\delta$ ) the shape is more determining factor than the particle size of the measured samples. With respect to flowability and energy, demandingness expressed by $\delta$ the spherical shape is preferable.

\section{Conclusions}

The aim of the work was to compare the mechanical and physical properties of metal powders used in additive productions of powders, which have not been used in production yet. The properties as the large particle size distribution and, above all, the particle shape, are the parameters that have a considerable influence on the resulting angle of internal friction. The angle of internal friction was selected as the primary characteristic quantity to demonstrate flow characteristics. As the used and 
the newly set metal powders are approaching the value of $30^{\circ}$ of their angle of internal friction, the description of possible particle transfer called the third type (1.3) of piston flow mechanism (1) was stated. An ideal powder conditions meeting the requirement of $30^{\circ}$ angle of internal friction were used.

Various metal powders were characterized in the study-stainless steel 316L, zinc, aluminum, tin, cooper, manganese, bronze, iron, titanium and ferrite powder. Particle size distribution, morphology and internal friction angles were determined for all of them. The possibility how to obtain preliminary (basic) information on the suitability of the use of metal powders for additive production from these primary, relatively fast physical methods was demonstrated.

The Karapatis derived criteria determined by particle size distributions indicated the need for further additional criteria from which the suitability of the use or modification of metal powders for additive production would be indicated.

The angle of internal friction (linearized and effective) was presented as another suitable characteristic of metal powders. For all 10 metal powders, the linearized and effective internal friction angle was found. This parameter was defined as the rate of loss of work when moving metal powder particles and the possibility of applying an internal friction angle model was demonstrated. For zinc powder, the effective internal friction angle of $29.9 \pm 0.5^{\circ}$ was found. This value indicates the predominance of the piston mechanism (1) of particle flow for motion type 3 metal powders. Reversing the application of the model makes it possible to analyze the internal friction angle for other new metal powders.

By applying the internal friction angle model, it has been suggested how to describe the ongoing movement of metal powder particles and to get insight into their behavior. However, the provisional application interval being merely valid for internal friction angle values ranging from $5.66^{\circ}$ to $30.36^{\circ}$ is the limiting factor.

With respect to the specified properties, 316L stainless steel, zinc powder and aluminum powder are the most suitable metal powders of this study for additive production. They contain spherical particles of uniform particle size distributions and exhibit the effective internal friction angle ranging from $28.6^{\circ}$ to $32.9^{\circ}$. These values ensure the suitable particle arrangement to form a homogeneous layer of material for 3D printing and other technologies within their flow properties.

Acknowledgments: This paper was conducted within the framework of the project LO1404: Sustainable development of ENET CENTRE-Energy Utilization of Non-traditional Energy Sources, CZ.1.05/2.1.00/19.0389: Research Infrastructure Development of the CENET (Centre of Energy Utilization of Non-traditional Energy Sources) and project Innovative and additive manufacturing technology-new technological solutions for 3D printing of metals and composite materials.

Author Contributions: Jiri Zegzulka and Daniel Gelnar conceived and designed the experiments. Daniel Gelnar and Lucie Jezerska performed the experiments. Alvaro Ramirez-Gomez and Jan Necas analyzed the data. Jiri Rozbroj contributed analysis tools. Lucie Jezerska and Daniel Gelnar wrote the paper.

Conflicts of Interest: The authors declare no conflict of interest.

\section{Nomenclature}

$c$

$d_{10}$

$d_{50}$

$d_{90}$

ffc
Cohesion $(\mathrm{Pa})$

$10 \%$ particle representation for the detected size, cumulative phase lower decile

$50 \%$ particle representation for the detected size, median

$90 \%$ particle representation for the detected size, cumulative phase upper decile

Flow function (-) 


\section{Greek Symbols}

$\delta$

$\delta_{\min }$

$\delta_{\max }$

$\phi$

$\phi_{\min }$

$\phi_{\max }$

$\sigma_{1}$

$\sigma_{\mathrm{c}}$

$\sigma_{\mathrm{sd}}$
Effective internal friction angle $\left(^{\circ}\right)$

Minimum value of effective internal friction angle $\left(^{\circ}\right)$

Maximum value of effective internal friction angle $\left({ }^{\circ}\right)$

Internal friction angle $\left({ }^{\circ}\right)$

Minimum value of internal friction angle $\left(^{\circ}\right)$

Maximum value of internal friction angle $\left(^{\circ}\right)$

Major consolidation stress $(\mathrm{Pa})$

Unconfined yield strength $(\mathrm{Pa})$

Standard deviation $\left(^{\circ}\right)$

\section{Abbreviation}

$\begin{array}{ll}\text { AM } & \text { Additive Manufacturing } \\ \text { DED } & \text { Direct Energy Deposition } \\ \text { EBM } & \text { Electron Beam Melting } \\ \text { SEM } & \text { Scanning Electron Microscope } \\ \text { SLM } & \text { Selective Laser Melting } \\ \text { SLS } & \text { Selective Laser Sintering } \\ \text { PBF } & \text { Powder Bed Fusion }\end{array}$

\section{References}

1. Seifi, M.; Salem, A.; Beuth, J.; Harrysson, O.; Lewandowski, J.J. Overview of materials qualification needs for metal additive manufacturing. JOM 2016, 68, 747-764. [CrossRef]

2. Murr, L.E.; Gaytan, S.M.; Ramirez, D.A.; Martine, E.; Hernandez, J.; Amato, K.N.; Shindo, P.W.; Medina, F.R.; Wicker, R.B. Metal fabrication by additive manufacturing using laser and electron beam melting technologies. J. Mater. Sci. Technol. 2012, 28, 1-14. [CrossRef]

3. Tan, J.H.; Wong, W.L.E.; Dalgarno, K.W. An overview of powder granulometry on feedstock and part performance in the selective laser melting proces. Addit. Manuf. 2017, 18, 228-255. [CrossRef]

4. Krystynova, M.; Dolezal, P.; Fintova, S.; Brezina, M.; Zapletal, J.; Wasserbauer, J. Preparation and characterization of zinc material prepared by powder metallurgy. Metals 2017, 7, 396. [CrossRef]

5. Clark, N.; Jones, N.; Setchi, R.; Porch, A. Particle size characterisation of metals powders for additive manufacturing using a microwave sensor. Powder Technol. 2017. [CrossRef]

6. Bertoli, U.S.; Guss, G.; Wu, S.; Matthews, M.J.; Schoenung, J.M. In-situ characterization of laser-powder interaction and cooling rates through high-speed imaging of powder bed fusion additive manufacturing. Mater. Des. 2017, 135, 385-396. [CrossRef]

7. Gu, D.D.; Meiners, W.; Wissenbach, K.; Poprawe, R. Laser additive manufacturing of metallic components: Materials, processes and mechanisms. Int. Mater. Rev. 2012, 57, 133-164. [CrossRef]

8. German, R.M. Prediction of sintered density for bimodal powder mixtures. Metall. Trans. A 1992, 23, 1455-1465. [CrossRef]

9. Hanzl, P.; Zetek, M.; Baksa, T.; Kroupa, T. The influence of processing parameters on the mechanical properties of SLM parts. Procedia Eng. 2015, 100, 1405-1413. [CrossRef]

10. Egger, G.; Gygax, P.E.; Glardon, R.; Karapatis, N.P. Optimization of powder layer density in selective laser sintering. In Proceedings of the 10th Solid Freeform Fabrication Symposium (SFF), Austin, TX, USA, 9-11 August 1999.

11. Spierings, A.B.; Herres, N.; Levy, G. Influence of the particle size distribution on surface quality and mechanical properties in AM steel parts. Rapid Prototyp. J. 2011, 17, 195-202. [CrossRef]

12. Spierings, A.B.; Levy, G. Comparison of density of stainless steel 316L parts produced with selective laser melting using different powder grades. In Proceedings of the SFF Symposium 2009, Austin, Texas, USA, 3-5 August 2009; Bourell, D.L., Crawford, R.H., Seepersad, C.C., Eds.; University of Texas at Austin: Austin, Texas, USA, 2009; pp. 342-353. 
13. Shinohara, K.; Oida, M.; Golman, B. Effect of particle shape on angle of internal friction by triaxial compression test. Powder Technol. 2000, 107, 131-136. [CrossRef]

14. Yousuff, M.; Page, N.W. Particle material, morphology and load effects on internal friction in powders. Powder Technol. 1993, 76, 155-164. [CrossRef]

15. Chan, L.C.Y.; Page, N.W. Particle fractal and load effects on internal friction in powders. Powder Technol. 1997, 90, 259-266. [CrossRef]

16. Zegzulka, J. The angle of internal friction as a measure of work loss in granular material flow. Powder Technol. 2013, 233, 347-353. [CrossRef]

17. Bowen, P. Particle size distribution measurement from millimeters to nanometers and from rods to platelets. J. Dispers. Sci. Technol. 2002, 23, 631-662. [CrossRef]

18. Markandeya, S.A.; Dhiman, N.; Shukla, S.P.; Kisku, G.C. Statistical optimization of process parameters for removal of dyes from wastewater on chitosan cenospheres nanocomposite using response surface methodology. J. Clean. Prod. 2017, 149, 597-606. [CrossRef]

19. Engeli, R.; Etter, T.; Hovel, S.; Wegener, K. Processability of different IN738LC powder batches by selective laser melting. J. Mater. Process. Technol. 2016, 229, 484-491. [CrossRef]

20. Peciar, P.; Kluka, M.; Briss, L.; Peciar, M. Determination of stress in particulate matter with DEM method. In Proceedings of the 39th International Conference of Slovak Sociaty of Chemical Engineering, Tatranské Matliare, Slovakia, 21-25 May 2012; Markos, J., Ed.; Slovak University of Technology in Bratislava: Bratislava, Slovakia, 2012; pp. 106-115.

21. Sogaard, S.V.; Pedersen, T.; Alleso, M.; Garnaes, J.; Rantanen, J. Evaluation of ring shear testing as a characterization method for powder flow in small-scale powder processing equipment. Int. J. Pharm. 2014, 475, 315-323. [CrossRef] [PubMed]

22. Schwedes, J. Review on testers for measuring flow properties of bulk solids. Granul. Matter 2003, 5, 1-43. [CrossRef]

23. Mihlbachler, K.; Kollmann, T.; Seidel-Morgenstern, S.; Jurgen, T.; Guiochon, G. Measurement of the degree of internal friction of two native silica packing materials. J. Chromatogr. A 1998, 818, 155-168. [CrossRef]

24. Zegzulka, J. An ideal Bulk Material. Bulk Solids Handl. 2002, 22, $214-221$.

25. Zegzulka, J. Granular states of material aggregation-A comparison of ideal bulk material with ideal fluid and ideal solid matter. Bulk Solids Handl. 2003, 23, 1-6. 